\title{
De esta ciudad terrena. La iglesia y el convento de San Agustín de Tunja
}

\author{
Of this Earthly City. The Church and the Convent \\ of San Augustin in Tunja
}

DOI: https://doi.org/I0.22380/20274688.1384

Recibido: 2 de julio del 2020
Aprobado: 26 de octubre del 2020

ABEL FERNANDO MARTÍNEZ MARTÍN* Universidad Pedagógica y Tecnológica de Colombia abelfmartinez@gmail.com

ANDRÉS RICARDO OTÁLORA CASCANTE**
Universidad Pedagógica y Tecnológica de Colombia
arotalorac@unal.edu.co

\section{R E S U M E N}

El artículo reconstruye la historia del convento de San Agustín de Tunja, conocido por su pintura mural, construido sobre el cercado del zaque, donde se levantó la ermita de Santiago a partir de la cual se desarrolla el conjunto. Se revisa el papel de personajes como el profeso agustino
Vicente de Requejada y la beata Antonia de Cabañas. A inicios del siglo XIX, fue posible contar con un inventario de la iglesia agustina, hoy vacía, realizado por la Orden de San Juan de Dios que ocupó el claustro luego de la supresión del convento agustino. Se logró identificar altares

* Decano y profesor asociado, Escuela de Medicina, Facultad de Ciencias de la Salud, Universidad Pedagógica y Tecnológica de Colombia (U PTC), Tunja, Colombia; director del grupo de investigación Historia de la Salud en Boyacá-uptc y del Museo de Historia de la Medicina y la SaluduptC, Tunja, Colombia; doctor y magíster en Historia, Universidad Pedagógica y Tecnológica de Colombia, Tunja, Colombia; doctor en Medicina y Cirugía, Universidad Nacional de Colombia, Bogotá, Colombia. https://orcid.org/0000-0002-4621-6072.

** Investigador del Grupo de Historia de la Salud en Boyacá-uptc, Universidad Pedagógica y Tecnológica de Colombia, Tunja, Colombia; doctor en Historia y magíster en Antropología, Universidad Nacional de Colombia, Bogotá, Colombia. Se desempeña profesionalmente en la Universidad Nacional de Colombia, Sede Bogotá, Colombia. https://orcid.org/0000-0002-0793-4602. 
e imágenes de lienzo y bulto que en la actualidad se encuentran descontextualizadas en otros lugares de la ciudad. Un espacio que fue diseñado para albergar la ciudad de Dios terminó convertido en terrena penitenciaría.

Palabras clave: convento de San Agustín, arte neogranadino, patrimonio mueble, Tunja, Colombia

\section{$\begin{array}{lllllllllllllllllll}\mathbf{A} & \mathbf{B} & \mathbf{S} & \mathbf{T} & \mathbf{R} & \mathbf{A} & \mathbf{C} & \mathbf{T}\end{array}$}

The article reconstructs the history of the convent of San Augustin in Tunja, which is famous for its mural painting, built on the Zaque enclosure, where the hermitage of Santiago was raised, from which the whole ensemble was developed. The role of characters such as the professed Augustinian Vicente de Requejada and the blessed Antonia de Cabañas. At the beginning of the $19^{\text {th }}$ century, an inventory of the Augustinian church, today empty, was carried out by the order of san Juan de Dios, who occupied the cloister after the abolition of the Augustinian convent. It was possible to identify altars and images of canvas and bulk that are currently decontextualized in other places of the city. A space that was designed to house The City of God, ended up turned into a penitentiary.

Keywords: convent of San Augustin, Neogranadine art, property heritage, Tunja, Colombia

\section{Introducción}

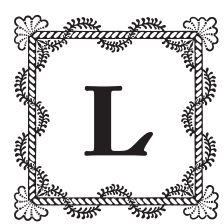

a historia del conjunto conventual de San Agustín de la andina ciudad de Tunja (Colombia), llena de múltiples vicisitudes, ha sido larga. San Agustín es un ejemplo sobreviviente de varias etapas de la ciudad; construido sobre el cercado del zaque muisca, fue lugar eje de la Conquista en agosto de 1537 . Luego de la fundación de la ciudad (I539) y de no pocos problemas, en 1582 los agustinos se establecieron definitivamente en la primitiva ermita de Santiago sobre la que construyeron la iglesia y el claustro, desde donde regentaron misiones en el altiplano y en los llanos entre los siglos XVI y XIx. La iglesia de San Agustín de Tunja fue lugar de manifestaciones religiosas como la de la beata Antonia de Cabañas, sepultada a finales del siglo xvir en la capilla de la Virgen de la Antigua.

Con la Independencia, a inicios del xix, la República suprimió el convento agustino y trasladó allí el Hospital de la Purísima Concepción de la Orden de San Juan de Dios hasta la extinción de la provincia hospitalaria en I835, aunque 
continuó como hospital. En I862 hubo un cambio radical en el conjunto al convertirse en cuartel, polvorín y, finalmente (I863), penitenciaría, con talleres de ornamentación, cantería, tejidos y alpargatería. La iglesia, retirada del culto, se convirtió en temido panóptico, el pequeño atrio fue convertido en una plazoleta interior y la portada quedó escondida hasta finales del siglo xx.

La mayoría de los trabajos existentes están enfocados en su uso como penitenciaría, de lo que hay información de archivo disponible, y en las innovaciones introducidas en su primera restauración en la década de 1980. El estado ruinoso del conjunto, luego de trasladada la penitenciaría a El Barne, en 1963, permitió a los restauradores dejar visibles todas las etapas históricas del conjunto. En la actualidad, el claustro de San Agustín está en una segunda restauración. Desde 1984 sirvió como área cultural del Banco de la República y alojó el Archivo Regional de Boyacá, con el valioso Archivo Histórico de Tunja, salas de conferencias y exposiciones. La iglesia fue destinada para biblioteca con una importante colección regional (Martínez, El claustro I25).

Existen pocos trabajos orientados a la historia de esta fundación agustina y a la descripción y análisis de la pintura mural del siglo XviI, ubicada en la monumental escalera y la segunda planta del claustro, así como en algunas de las paredes de las tres capillas y la nave central de la iglesia ${ }^{1}$. Esta pintura se une a otra más tardía del siglo xviı y a la pintura mural penitenciaria, con cartillas de moral decimonónica y tablas de aritmética restauradas y descritas por Rodolfo Vallín durante la primera restauración. Hasta ahora no existen trabajos sobre las imágenes que acompañaron el conjunto conventual de agustinos calzados en la ciudad, descontado lo relativo a la pintura mural. En general, el claustro y la iglesia resultan un espacio vacío, sin imágenes. Cuando dejó de ser usado como hospital de caridad en el siglo xIX y la iglesia pasó a contener 73 celdas de castigo vigiladas desde el antiguo coro —el sueño del panóptico de Jeremías Bentham-, se inició una diáspora de altares, retablos, cuadros e imágenes de bulto hacia distintas iglesias de la ciudad.

Las apresuradas circunstancias en las que se produjo la supresión del convento agustino en I822 hacen difícil rastrear su archivo. No obstante, los

I Los trabajos sobre la orden en Colombia, Venezuela y Ecuador están publicados en revistas agustinas por miembros de la orden. Se destaca el trabajo de José Pérez Gómez (o. S. A.) en 1923 en Archivo Histórico Hispano-Agustiniano, hoy Archivo Agustiniano, donde Fernando Campo del Pozo publicó los artículos más extensos sobre la orden en Colombia, pocos sobre Tunja. De la misma manera, las Centurias Colombo-Agustinas de David Mucientes (o. s. A.). 
cambios producidos al asumir la República el Patronato Real luego de I8I9, con el pleito por el local del colegio de la expulsada Compañía de Jesús, donde se encontraba desde 1778 el convento de la Orden de San Juan de Dios y el Hospital de la Purísima Concepción de la ciudad y su traslado al suprimido convento agustino, permiten tener un inventario correspondiente al año I832 que combina la imaginería y las devociones agustinas, jesuitas y hospitalarias (Martínez y Otálora 168). Este, el primero hallado, ha sido empleado para reconstruir la historia del hospital y permite visualizar el patrimonio mueble que contuvo la iglesia, hoy en día vacía, y su posible localización en otros espacios de la ciudad, donde permanecen anónimos, mal identificados a veces, pero descontextualizados siempre.

El valioso manuscrito sobre la vida de la beata Cabańas, primer testimonio de beaterios en el Nuevo Reino de Granada, escrito por su confesor jesuita en el siglo XVII, es otro documento utilizado para reconstruir la historia visual de la iglesia agustina.

El expolio del patrimonio mueble en Tunja, ciudad que se convirtió a finales del siglo Xvi en un importante centro cultural y taller que proveía a las iglesias doctrineras y a las villas asentadas en su jurisdicción ha sido constante desde el siglo Xix. Los múltiples y más variados usos que la República dio a los claustros coloniales de las expropiadas órdenes religiosas produjeron parte de la diáspora de las obras artísticas que se recombinaron en templos que siguen sirviendo para el culto católico.

A pesar de un interés inicial por la historia del arte en la ciudad a mitad del siglo xx, luego del cuarto centenario de su fundación (1939) y la restauración de los claustros y templos sobrevivientes para 1989, cuando se inició la recuperación del centro histórico, la mayoría de los trabajos no tuvo en cuenta estos cambios de lugar que convirtieron a los templos restaurados en palimpsestos por descifrar, sumado a la ausencia de inventarios y catálogos museales rigurosos, así como la falta de consolidación de los escasos museos existentes y la titularidad del patrimonio (Colmenares I56). Así mismo, la mayoría de ellos se dedica a la arquitectura, la pintura mural y las consideraciones generales sobre la retablística neogranadina. Este trabajo rastrea y reconstruye la diáspora del patrimonio agustino en distintas iglesias y museos de la ciudad, por medio del estudio de las manifestaciones artísticas de tres órdenes religiosas que tuvieron asiento en Tunja, y muestra cómo las obras de arte itinerantes se desplazan por el damero de la ciudad. 


\section{Los agustinos en Tunja}

El trabajo de los muiscas en las encomiendas se convirtió en el sustento económico de este mundo andino. La introducción del trigo trajo consigo la articulación de rutas comerciales del altiplano hasta el puerto de Cartagena de Indias en el Caribe y hasta la Audiencia de Quito. Tunja se convirtió en un centro artístico que reproducía en sus talleres los ideales del humanismo católico peninsular. Un reducto cultural de los europeos representados en el Cabildo y las órdenes religiosas instaladas en la ciudad, centro de la evangelización de un vasto territorio, en constante enfrentamiento político con la Real Audiencia de Santafé.

Un siglo duró este esplendor encomendero, tiempo en el cual se levantaron las principales casas con portadas blasonadas y techumbres con programas iconográficos, se construyó la iglesia mayor, seis ermitas, dos conventos femeninos y cinco masculinos. Las pestes de finales del siglo XVI y primeras décadas del Xvir produjeron el colapso demográfico de los indígenas que sustentaban el modo de producción y la riqueza de la ciudad, que se estancó.

En 1549, diez años después de la fundación, se solicitó al Cabildo el establecimiento de un convento agustino, solicitud que fue negada. En I55I los dominicos fundaron un convento sobre el cercado del zaque, lugar que abandonaron para pasar a una mejor ubicación cerca de la plaza Mayor. En I574, los agustinos de la provincia de San Miguel de Quito realizaron una ceremonia de fundación en la plaza de abajo, tres cuadras al nororiente de la plaza Mayor, que empezó a llamarse de San Agustín. En un bohío que servía de ermita, fray Juan Núñez tomó posesión del lugar, donde vivió diez meses junto con dos religiosos, cuando el vicario eclesiástico Juan de Leguizamón expulsó a los agustinos y demolió sus bohíos. La escena fue violenta y Núnez, herido en una mano, trasladó el Santísimo Sacramento a la iglesia mayor entonando el salmo In exitu Israel de Egipto. Luego salieron de la ciudad rumbo al convento agustino de Santafé (Mucientes I8).

Los agustinos llegarían finalmente a Tunja a través de un tortuoso proceso, que inició con el profeso agustino Vicente de Requejada, quien se encontraba en el Caribe desde 1527 (Campo del Pozo, "Fuentes" 258). Requejada vino como capellán de la tropa de Nicolás de Federmán y luego del campamento de Santafé (I538) se trasladó con Gonzalo Suárez Rendón para fundar Tunja, donde celebró la primera misa el día de la Transfiguración de 1539, con una rústica cruz conservada como reliquia en la iglesia Mayor (Mucientes i9). Fue el primer párroco de la ciudad, de donde salió después con Hernán Pérez de Quesada a 
la expedición de El Dorado, cuando convirtió su jumento en gastronómico experimento: "Y el padre fray Vicente de Requejada [...] el cuero le quitó de las costillas / y convirtió las tripas en morcillas" (Castellanos 570).

Requejada se instaló nuevamente en Tunja y disfrutó de la encomienda de Obeita. En 1568 fue testigo para otorgar el beneficio de la iglesia mayor a Juan de Castellanos. En el testimonio figura como clérigo presbítero (Rojas 25I). En I575 murió, a los 67 años, en Leiva. Su testamento causó un grave conflicto entre el beneficiado Castellanos y el prior agustino de Santafé, ya que en su testamento Requejada se reconoció agustino y advirtió que como fraile no podía testar. Solicitó ser enterrado en la iglesia mayor, con hábito agustino; enumeró sus bienes, los cuales destinó a la erección de la iglesia mayor, y nombró albacea a su amigo Castellanos (Rojas 263).

Al poco tiempo, Castellanos presentó un escrito ante el corregidor en el que declaraba que Requejada había sido clérigo en Tunja por más de cuarenta años, tiempo en que no había vestido el hábito agustino, por lo cual, en cumplimiento del testamento, la iglesia mayor de la ciudad era beneficiaria. Informaciones de testigos recogidas por Castellanos aseguraban que el hábito lo había abandonado al volver de El Dorado y lo vistió nuevamente tres años antes de morir. El prior agustino de Santafé, Jerónimo de Guevara, con el argumento de que Requejada era agustino, inició la reclamación de la totalidad de los bienes (Rojas II7-I25). Finalmente, la Real Audiencia decidió repartir los bienes de Requejada entre la iglesia Mayor, la fundación del noviciado agustino en Tunja, el convento de Santafé y el de Zaragoza, de donde era natural (Paniagua 194-195).

En medio de la disputa, los agustinos volvieron nuevamente a Tunja (I578) y tomaron posesión de la ermita de Santiago. El Cabildo le permitió al padre Luis de Quesada establecerse en Tunja, en el mismo sitio de donde habían sido expulsados tres años atrás. Con los fondos de Requejada, los agustinos compraron los solares contiguos repartidos entre los herederos de Juan Rubio y el capitán Alonso Maldonado, encomendero de Duitama, cuya familia estuvo vinculada por vecindad al convento y varios de sus miembros fueron enterrados en la iglesia (Campo del Pozo, "Historia" 285-286).

En I582, una vez repartida la problemática herencia de Requejada, de la cual su hijo natural Martín Sánchez de Requejada no vio parte, los agustinos empezaron a hacer vida religiosa en la ciudad. Del convento dependieron algunas doctrinas como Boyacá, Sotaquirá, Cómbita, Susa, Motavita, Tinjacá y anexos, Socha, Tasco, Chita, La Salina y algunas en los llanos (Mucientes 33). 
En 1580 , un agustino del convento de Tunja inició una nueva fundación en la villa de Leiva.

Cuatro años después, fray Lorenzo de Rufas presentó al Cabildo los planos de la iglesia, cuya construcción terminó en 1603 (Campo del Pozo, "Historia" 286). En la descripción de Tunja de i6ıo, llevada a cabo por Pedro de Valencia, se refiere al convento de San Agustín como más moderno, que no alcanzó el buen tiempo de los de Santo Domingo y San Francisco: "tiene muy pequeña y baja iglesia y la habitación de los frailes es una casa cubierta de paja que por su mucha pobreza aún no han podido cubrirla de teja" (BNE, Valencia, f. 264 v.), lo que pone en evidencia que el convento y su pintura mural no pueden ser anteriores a I6Io (figura I).

El de Tunja fue el segundo convento de la provincia de Nuestra Señora de Gracia con centro en Santafé (I575), sobrepasando a Cartagena (I580). La provincia se constituyó por escisión de la de San Miguel de Quito, en el capítulo general de I6or (Paniagua 196). En el siglo Xvir se estableció en el convento un noviciado con treinta religiosos (JCBL, Torres 734).

El claustro está compuesto por cuatro galerías dobles, con columnas toscanas y arcos de medio punto que encierran el amplio patio interior. En el segundo piso existen distintos tipos de arcos (medio punto, carpanel y herradura). Se destaca por su monumentalidad la escalera imperial, construida con grandes piedras, desgastadas por el paso del tiempo y de los hombres, que se bifurca en la mitad de su trayecto para ascender al segundo piso, cuyas paredes están decoradas con pintura mural de ángeles. Esta escalera se construyó en tiempo del prior Juan Adame de Montemayor.

Cuando se realizó la primera restauración, bajo los pañetes de los muros se encontró pintura mural de dos épocas: una de muy buena calidad, que corresponde a la época de construcción del claustro e iglesia y representa escenas de la vida de san Agustín, y otra más tardía, fresca y barroca, que llena de flores los espacios (Vallín i32).

La iglesia, de una sola nave con bóveda falsa de medio cañón rebajado, posee un coro alto. En el centro de la nave, al lado de la epístola, se abre una puerta dintelada que da acceso al claustro. En el crucero se sitúan dos capillas a modo de brazos. En el lado de la epístola, al sur, se encuentra otra capilla alargada lateral que corresponde a la fundacional ermita de Santiago. En la iglesia se observa la decoración azul profundo de la pintura mural y cartelas en capillas y paredes altas. 


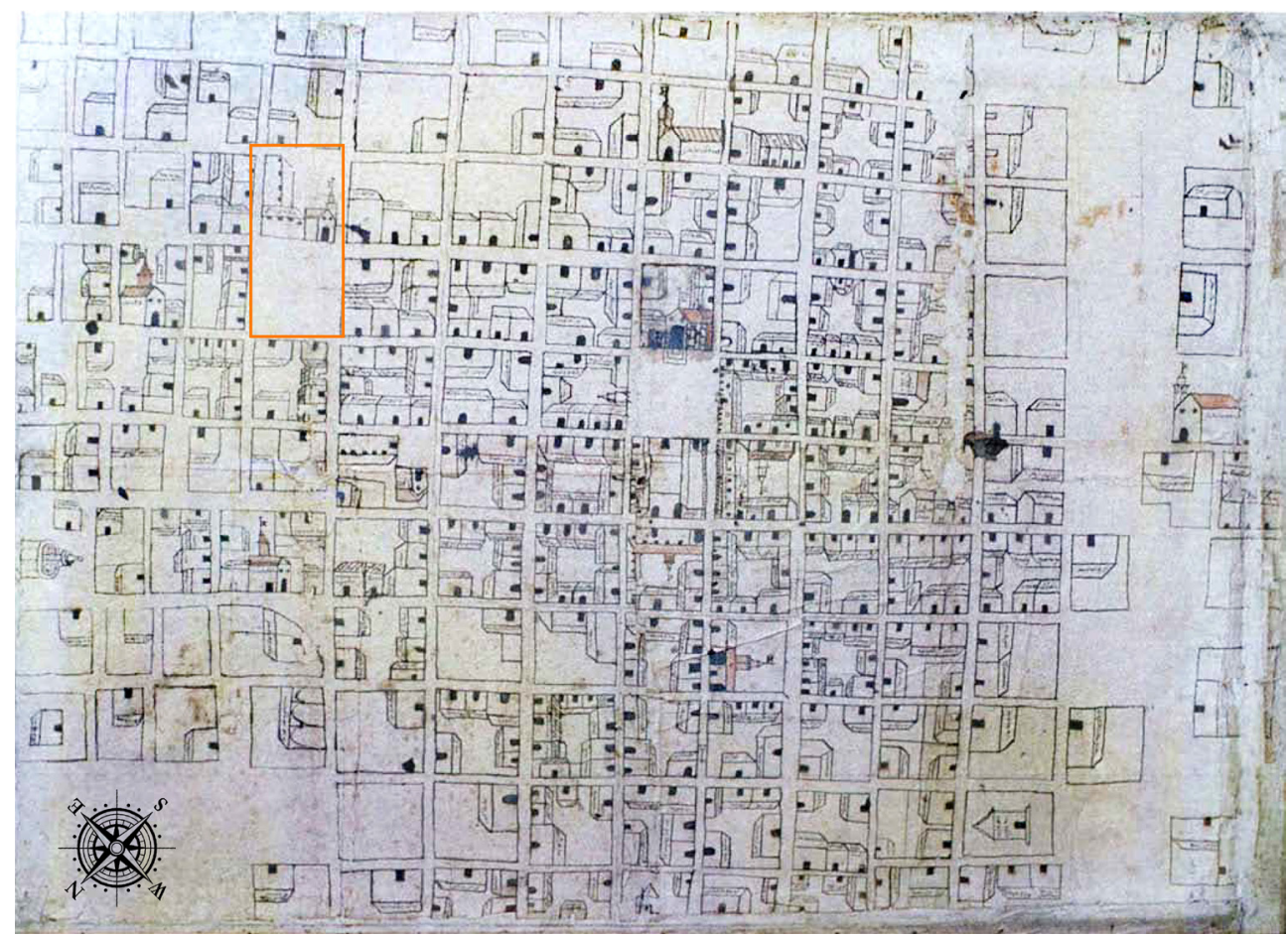

$\bullet$ FIGURA I.

Plano de la ciudad de Tunja de I623

La iglesia y la plaza mayor marcan el centro del mapa de repartición de parroquias de I623. Tres cuadras al nororiente, tras un pronunciado descenso, se encuentra la plaza de abajo con el convento de san Agustín (en recuadro naranja) y más al norte la ermita de Las Nieves. Las órdenes religiosas en la ciudad se encuentran en la cercanía de la parroquia mayor, correspondiendo a los agustinos una periférica localización en un arrabal de difícil acceso por cárcavas y lodazales, que empeoró tras el estancamiento urbano del siglo xvir que lo dejó a las afueras a inicios del xIx, lugar adecuado para ubicar el hospital.

Fuente: Curia Arzobispal de Tunja, con modificaciones de elaboración propia

La fachada de la iglesia de San Agustín es de las más vistosas de Tunja. Influida por el último Renacimiento y el inicio del Barroco, predominan los aspectos geométricos en estructura y ornamentación (Paniagua 199). Sebastián describe la espadaña como: "una de las primeras de la larga serie neogranadina; tiene un basamento decorado con recuadros manieristas para producir efectos de claroscuro y dos cuerpos con arcos de medio punto entre pilastras y pináculos piramidales terminados en bolas" (Sebastián, Álbum xviıI). 


\section{La ciudad de Dios}

Agustín ${ }^{2}$ fue el primer pensador medieval de la Iglesia católica. En sus Diálogos, la búsqueda de la sabiduría coincidente con la felicidad, producto de las discusiones sostenidas con sus alumnos y con su madre Mónica³, "representa el punto de vista de la fe, que se integra al de la filosofía” (Parodi 35I-353). Fue nombrado obispo de Hipona, en África, donde exploró la relación entre la fe cristiana y la cultura pagana.

En La ciudad de Dios, Agustín hace una interpretación teológica de la historia de Roma (Chuaqui 279). Las dos ciudades, la terrenal, Roma y sus tradiciones, y la divina, conviven en el mismo tiempo y espacio en una nueva y más lograda reflexión de la relación entre cristianismo y cultura pagana. Es la primera tentativa compleja de

proponer dentro de la nueva cultura, una filosofía de la historia, que Agustín logra construir gracias a su capacidad de pensar a la humanidad como un organismo viviente, único, que tiene como base una misma ley de desarrollo y de imaginar el entero curso de la historia como un camino dotado de sentidos. (Parodi 357)

Los preceptos monacales formulados por san Agustín empezaron a ser reivindicados en el siglo XıII. Así, los dispersos monjes ermitaños obtuvieron la confirmación de la orden agustina con el apoyo del papa Bonifacio VIII (I298), con el permiso para construir su iglesia en Roma (Sebastián, Contrarreforma y Barroco 269). La orden siguió la regla creada por Agustín en el siglo IV y se convirtió en la tercera orden mendicante surgida en el siglo XIII, tras franciscanos y dominicos. En el siglo XVI se presentaron varios movimientos mesiánicos en Europa y el Nuevo Mundo, parte de una corriente de espiritualidad medieval en la que reapareció el milenarismo (Kamen 360).

Los agustinos decoraron sus conventos con los temas de la vida de su fundador (Sebastián, Contrarreforma y Barroco 270). En tal sentido, la repetición de

2 Sus obras principales son La ciudad de Dios y Las confesiones, de donde proviene la mayor parte de su iconografía, como el corazón traspasado. Se le representa como doctor de la Iglesia, con libro, pluma o maqueta en calidad de fundador. En el siglo Xvi se impuso su representación como anciano barbado vistiendo hábito agustino, o bien como obispo (Carmona i8).

3 La madre de Agustín es representada con hábito agustino y velo (Carmona 17). 
las series de la vida de san Agustín "muestra la necesidad de fijar un relato, de convertirlo en un modelo canónico" (Sigaut IOI).

La escalera del convento agustino tiene sentido iconográfico, lugar de paso entre el claustro bajo y el alto, especie de sanctasanctórum reservado a la vida privada de la comunidad. Esta abundancia de ángeles, que no aparece en otra parte del convento, sería una alusión a la ascensión simbólica a la ciudad de Dios, flanqueados por otros símbolos agustinos como el corazón traspasado, el báculo y la mitra. Las escenas de la vida de san Agustín con cartelas tomadas no literalmente del Eclesiastés y de La ciudad de Dios, reflejan el orden, la justicia y la paz de la ciudad celestial (Paniagua 205).

El interior de la iglesia está cubierto de pintura mural, la cartela de la capilla de Ana de Otálora (I62I) da una pista de la fecha de la decoración. Una bula de Sixto V, de 1586, otorgaba indulgencia plenaria a quienes escogieran la iglesia como lugar de sepultura, como lo hicieron Ana de Otálora y la beata Antonia de Cabañas (Paniagua 2II).

\section{La beata Antonia de Cabañas y la iglesia de San Agustín}

En el siglo Xvir la iglesia agustina no tenía bancas, las piadosas acudían a misa con sus criadas y sus tapetes por comodidad e higiene, verdaderos estrados de herencia mudéjar que despertaban la envidia de aquellas otras que aguantaban estoicamente el frío suelo (López 93). Una de sus más asiduas visitantes fue Antonia de Cabañas (I629-I667). Sobre su vida existe un manuscrito del siglo $\mathrm{XVII}^{4}$, atribuido por Pedro de Mercado al jesuita Diego Solano (Mercado 435).

No hay descripciones de beaterios 5 en el Nuevo Reino de Granada, la beata tunjana habitaba el arrabal de Las Nieves y era devota de san Agustín cuya iglesia quedaba cerca de su casa. Las experiencias místicas de esta mujer, nacida en el siglo XVII, siguen las mortificaciones y los ejercicios espirituales jesuitas, pero sus arrebatos místicos y las largas jornadas de oración las hacía en

4 El manuscrito atribuido al confesor de la beata que proviene del Colegio de la Compañía de Jesús de Tunja se encuentra en la Biblioteca Nacional de Colombia.

5 La mujer con vocación religiosa que no entraba en un monasterio se convertía en beata. Vivía aislada en su casa convertida en beaterio, solía tomar algún voto y mantenía contacto con una orden religiosa masculina (Kamen 360). 
la iglesia de San Agustín, donde fue enterrada en el más puro ritual barroco en la capilla de la Virgen de la Antigua, amortajada con el hábito agustino.

El manuscrito está dedicado a san Agustín, cuya fiesta era celebrada todos los años por la familia Cabañas, que cubría el gasto de velas, el adorno de la iglesia, de la imagen del Niño Jesús y de san Agustín. Los hermanos de Antonia, clérigos, ocupaban la prédica en el púlpito y el coro cantando la misa en la fiesta. El confesor jesuita comparó a Antonia con el "sol africano" por sus virtudes de caridad cristiana (BNC, SLRM, Solano). Era la encargada de organizar y arreglar los altares, así como vestir la estatua del patrono, a quien le confeccionaba vistosos vestidos con joyas (BNC, $S L R M$, Solano, f. I2 r.). El jesuita señala que la familia Cabañas era de alguna prestancia, aunque fue por falta de dote que Antonia no entró a un convento, por lo que decidió convertir la casa familiar en beaterio, del que solo salía para ir a la iglesia de San Agustín, cuyos frailes eran cercanos a la familia.

Las mortificaciones de Antonia le empezaron a producir distintas afecciones de salud: pasaba el Jueves Santo velando el santísimo, y en la madrugada de un Viernes Santo, ante las imágenes del crucificado y la Virgen, tuvo una de sus primeras experiencias místicas y decidió salir a andar las estaciones calzada con garbanzos dentro de los zapatos y enfermó (BNC, $S L R M$, Solano, f. I4 v.).

Al morir su padre, Antonia empezó a leer las vidas de santos, en textos que le prestaba su hermano, cura doctrinero del cercano pueblo de indios de Soracá. Así leyó las cartas de san Pablo en la interpretación de san Agustín en su polémica con los pelagianos, lo que la llevó a hacer confesión general de su vida, y luego empezó a practicar los ejercicios espirituales de san Ignacio, con sus severas disciplinas, y tomó votos de pobreza, castidad y obediencia (BNC, SLRM, Solano, ff. 23 v., 27 r., 39 v.). La beata se levantaba antes del alba y acudía a misa a San Agustín, después se ponía a coser o confeccionar ornamentos y velos para los altares de la iglesia, y al Niño Jesús le confeccionaba ropa con hilo de oro y seda. Tenía devoción a la Trinidad, la Inmaculada, san José y el Calvario (BNC, $S L R M$, Solano, ff. 74 v., IO8 r., I45 v., I6I v.), imágenes que se encontrarán en el inventario de la iglesia agustina en I832.

Una mañana, en tiempo de cuaresma, tras salir de misa y orar ante la imagen de san Antonio Abad, empezó a oír la campanilla del santo ermitaño en la plaza de san Agustín y anunció su propia muerte, que ocurrió, en efecto, la mañana del 28 de marzo de I667.

La rigidez cadavérica dio un último toque de patetismo a la barroca escena, ya que el cuerpo sin vida de Antonia se vistió con el hábito agustino, con toca y 
una cruz en las manos. El entierro de la beata fue un acontecimiento en Tunja: asistieron el corregidor y justicia y todas las religiones y cofradías con estandartes, particularmente los indios de Soracá con música, encabezados por los agustinos en cuya iglesia se celebraron los oficios, durante los cuales se dispuso el féretro de la mujer en la tumba de su padre. A los dos años los agustinos cambiaron el cajón por uno más adornado y la inhumaron en la capilla de la Virgen de la Antigua, al lado de una peana, donde sus reliquias empezaron a recibir visitas. Trozos de su hábito y cabellos se usaron con fines taumatúrgicos en el real convento de Santa Clara, y la camándula, que conservaba su confesor en el Colegio de la Compañía, se usaba contra las cataratas (BNC, SLRM, Solano, ff. I66 v., I70 v.-I78 v.).

\section{De convento a hospital}

El Hospital de Tunja, ubicado desde 1777 en el claustro jesuita, esquina de la plaza Mayor, empezó a causar numerosas protestas por su poco higiénica localización. En 1784 el Cabildo solicitó al virrey el traslado al convento de agustinos calzados, "en la parte inferior y salida de esta ciudad, por donde siguen los vientos sin retroceder", no contaminando la ciudad con los pútridos miasmas de sus enfermerías, letrinas y cementerio (Agudelo 885).

Con el fin de la guerra de independencia se inició la organización de un nuevo Estado bajo la forma de una república, que tomó medidas para el control y la creación de instituciones educativas y de salud pública (Fundación I2I-I22). El gobierno asumió el antiguo Patronato Real (I820), por lo que las comunidades religiosas, el clero secular y los hospitales quedaron bajo su tutela directa (Young 37). La República introdujo cambios en la administración y el funcionamiento de los hospitales de san Juan de Dios. El de Tunja pasó del exconvento de la Compañía al convento agustino suprimido por el Gobierno en la década de I820, donde se harían cargo de la iglesia de San Agustín con sus alhajas, altares e imágenes (Fundación 56).

En I822 se estableció un colegio republicano en Tunja, para lo cual se ordenó que los agustinos calzados abandonaran su claustro y se trasladaran al convento descalzo de El Topo, a extramuros de la ciudad. Los agustinos solicitaron pasar al convento suprimido de la misma orden en Leiva. El 20 de junio de I822, la República ordenó que: "El Hospital de San Juan de Dios se traslade al Convento de Agustinos Calzados de la ciudad, para que aquel sirva de establecimiento al Colegio de Boyacá" (Mier I04-IO5). El alcalde de Tunja 
visitó el abandonado convento agustino con carpinteros y albañiles y llegó a la conclusión de que el claustro se encontraba en condiciones satisfactorias en sus catorce piezas, enfermería e iglesia y que únicamente la ropería y la cocina necesitaban reparación: "es sano, apropiado para servir de Hospital ya que sus edificaciones estaban capacitadas" (Agudelo 864).

El hospital se vio reducido con el traslado al convento agustino, no solo en su espacio físico, sino en el número de hospitalarios, de camas, de hombres y mujeres y recursos económicos para el mantenimiento del convento-hospital, cuya administración pasó por la fuerza al síndico, representante del Gobierno.

Gracias a las visitas realizadas a los hospitales de la orden de san Juan de Dios, se cuenta con un inventario correspondiente al 5 de agosto de I83I que menciona la iglesia con sus altares (AHC, $S C O A$, Carta cuenta I83I). Fray Tomás Cárdenas, visitador de la orden, nueve meses después se convertiría en administrador, y en el ejercicio de ese cargo escribió una carta cuenta e inventario de la iglesia para remitir al provincial hospitalario el 3 de mayo de 1832 (AHC, SCOA, Carta cuenta 1832). Esta es la única descripción, hasta ahora encontrada, de la iglesia agustina que tiene una portada de cantería con la estatua en piedra del obispo de Hipona, una espadaña con tres campanas que remata la fachada, una cruz y una veleta. Tiene "su buen cañón de iglesia con diez altares [...] y a la derecha, una capilla con seis altares", combinación de santos y advocaciones de los hospitalarios, otros traídos de la iglesia de los jesuitas y los altares e imágenes dejadas por los agustinos. En la tabla i se presenta el inventario de la nave central.

$\leadsto$ TABLA I.

Inventario de la nave central de la iglesia del Hospital de Tunja

\begin{tabular}{|l|l|l|}
\hline \multirow{4}{*}{ Altares e imagen principal } & \multicolumn{1}{|c|}{ Cuadros } & \multicolumn{1}{|c|}{ Estatuas de bulto } \\
\hline \multirow{2}{*}{$\begin{array}{l}\text { Mayor dorado de tres cuerpos } \\
\text { con san Juan de Dios de bulto } \\
\text { y sagrario redondo }(\mathbf{A})\end{array}$} & Santa Catalina de Siena & San Rafael \\
\cline { 2 - 3 } & María Magdalena & San Carlos Borromeo \\
\cline { 2 - 3 } & Virgen de Belén & San Domingo \\
\cline { 2 - 3 } & & Niño Jesús \\
\cline { 2 - 3 } & & $\begin{array}{l}\text { El Salvador } \\
\text { Dos efigies de la religión } \\
\text { de san Agustín }\end{array}$ \\
\hline
\end{tabular}




\begin{tabular}{|c|c|c|}
\hline Altares e imagen principal & Cuadros & Estatuas de bulto \\
\hline $\begin{array}{l}\text { Dorado de la Virgen de la } \\
\text { Luz (B) }\end{array}$ & San Ignacio & \\
\hline $\begin{array}{l}\text { Dorado de la Virgen de } \\
\text { Loreto }(\mathrm{C})\end{array}$ & & $\begin{array}{l}\text { Dos santos en medio } \\
\text { relieve }\end{array}$ \\
\hline \multirow{5}{*}{ Salvador de Horta (D) } & Santa Bárbara & \\
\hline & San José & \\
\hline & $\begin{array}{l}\text { San Agustín con santa } \\
\text { Rita y san Nicolás }\end{array}$ & \\
\hline & San Cristóbal & \\
\hline & Virgen del Rosario & \\
\hline \multirow{4}{*}{$\begin{array}{l}\text { Dorado del tránsito de san } \\
\text { Juan de Dios (cuadro) (E) }\end{array}$} & La Trinidad & \\
\hline & $\begin{array}{l}\text { Pasión de Jesús } \\
\text { Nazareno }\end{array}$ & \\
\hline & Virgen del Rosario & \\
\hline & San Antonio Abad & \\
\hline \multirow{3}{*}{ San Francisco de Borja $(\mathbf{F})$} & Virgen de la Soledad & \\
\hline & Virgen de Guadalupe & \\
\hline & Santa Teresa de Jesús & \\
\hline \multirow{5}{*}{$\begin{array}{l}\text { Dorado de san Juan } \\
\text { Nepomuceno y sagrario con } \\
\text { san Luis Gonzaga }(\mathbf{G})\end{array}$} & $\begin{array}{l}\text { Señor de la Columna } \\
\text { con san Pedro }\end{array}$ & \\
\hline & $\begin{array}{l}\text { Niño Jesús con la } \\
\text { Verónica }\end{array}$ & \\
\hline & Virgen de los Dolores & \\
\hline & San Cayetano & \\
\hline & $\begin{array}{l}\text { Niño Jesús como buen } \\
\text { pastor }\end{array}$ & \\
\hline
\end{tabular}




\begin{tabular}{|c|c|c|}
\hline Altares e imagen principal & Cuadros & Estatuas de bulto \\
\hline \multirow{5}{*}{ Calvario $(\mathbf{H})$} & San Nicolás de Bari & $\begin{array}{l}\text { Crucificado con san } \\
\text { Juan y la Magdalena } \\
\text { vestidos de lienzo }\end{array}$ \\
\hline & $\begin{array}{l}\text { Nuestra Señora del } \\
\text { Tránsito }\end{array}$ & \\
\hline & Santa Teresa de Jesús & \\
\hline & Inmaculada & \\
\hline & Virgen de Belén & \\
\hline \multicolumn{3}{|l|}{ Jesús Nazareno (cuadro) (I) } \\
\hline $\begin{array}{l}\text { Coro con órgano y dos } \\
\text { facistoles }\end{array}$ & San Nicolás de Bari & $\begin{array}{l}\text { En la mitad una gran } \\
\text { cruz con Cristo pintado }\end{array}$ \\
\hline \multicolumn{3}{|l|}{ Viacrucis } \\
\hline \multicolumn{3}{|l|}{$\begin{array}{l}\text { Dos pilas bautismales de } \\
\text { piedra }\end{array}$} \\
\hline Cancel de lienzo pintado & & \\
\hline
\end{tabular}

Fuente: AHC, SCOA, Carta cuenta I832

En el altar mayor del templo de la Compañía de Jesús, clasificados como un santo jesuita y una santa Ana (altar dedicado a la Inmaculada), se encuentran en realidad dos imágenes de bulto del siglo xvir que corresponden al antiguo patrono de la iglesia de San Agustín y a su madre santa Mónica, con sus hábitos. En 1939, el historiador académico Rafael Salamanca Aguilera señaló en su Guía histórica que en la sacristía de la iglesia jesuita "existen reliquias muy preciadas de santa Mónica y de san Agustín” (Salamanca 38). Estas imágenes pueden corresponder a las descritas en el tercer cuerpo del altar mayor en I832 y pudieron ser trasladadas en I863. Debe recordarse que en diciembre de I830, Rafael Urdaneta, tras asumir la dictadura, restableció el convento de agustinos calzados, considerando que el colegio de Boyacá no podía subsistir, y entregó a la provincia de agustinos de Bogotá el colegio, la antigua iglesia de los jesuitas y sus alhajas y bienes (Mier 1329-I33I). 
Con respecto a las estatuas del altar mayor, san Juan de Dios, el arcángel Rafael, san Carlos Borromeo y santo Domingo, debe decirse que estas provienen de la primitiva iglesia del Hospital de la Purísima Concepción, pasaron a la iglesia de los jesuitas y estaban en San Agustín en I832 (Martínez y Otálora 173). En la pequeña recoleta agustina descalza de El Topo, de inicios del siglo XviıI, ubicada al pie de la loma de los Ahorcados, al occidente, hay dos retablos barrocos en dorado y rojo con los tres soportes de la escuela de retablos tunjana, uno con un cuadro de san Antonio Abad y en el remate un Niño Jesús como buen pastor. El retablo del frente fue rehecho con imágenes modernas.

En la iglesia de Las Nieves, uno de los altares laterales, barroco en dorado y rojo y de tres columnas, hoy dedicado a la patrona de los salesianos María Auxiliadora, contiene los cuadros de santa Teresa de Jesús y san Agustín, una Virgen del Rosario y un Niño Jesús de la espina. Otro altar lateral de la iglesia tiene un medio relieve del degüello de san Juan Bautista con un cuadro del Señor de la Columna.

En el convento de los franciscanos de Tunja hay una curiosa composición al óleo que tiene a la izquierda a san Juan de Dios con sus atributos y descalzo, a la derecha san Cristóbal y en el medio la Inmaculada. En la casa del Escribano del Rey hay tres cuadros, uno de santa Bárbara como el del altar del mendicante catalán Salvador de Horta, uno pequeño de san Antonio Abad como el del remate del retablo del tránsito y un Jesús como buen pastor, como el del altar de san Juan Nepomuceno.

Los historiadores del arte Francisco Herrera y Liliana Vargas al referirse al retablo del Humilladero consideraron que podía corresponder a uno que en la actualidad se encuentra en la iglesia de Santa Clara la Real (Herrera y Vargas 227). Este altar corresponde, en la descripción de I832, al altar de la Virgen de Loreto, debido a los dos santos agustinos en medio relieve que lo acompañan aún. El altar tenía en su parte superior lo que parece ser un san Agustín con una lámpara de aceite encendida, analogía del misterio de la Encarnación; además, permanecen pintados el sol y la luna, símbolos agustinos de La ciudad de Dios. La antigua iglesia de las clarisas, que sirvió como hospital de caridad desde I863, alberga otras imágenes relacionadas con la antigua iglesia de San Agustín.

En 1940 cuando las hermanas de la Presentación administraban el local del hospital, devolvieron la estatua de san Juan de Dios que ocupaba el altar mayor de la iglesia a los retornados hospitalarios, quienes la trasladaron a Bogotá, donde se encuentra (Martínez y Otálora i65). 
En el patio del claustro y junto a la puerta que da acceso a la iglesia de San Agustín, se encontraban cuatro andas de pasos de Semana Santa, un ataúd de la hermandad del Espíritu Santo, dos cruces, dos Verónicas y dos facistoles, lo cual demuestra que en la iglesia agustina había estación de penitencia durante la Semana Mayor.

La antigua ermita de Santiago, convertida en dos capillas, una para camarín de una imagen traída de la iglesia de los jesuitas, la Virgen de los Dolores, y otra para depósito, se describe en la tabla 2.

$\leftrightarrow$ TABLA 2.

Inventario de la capilla de la Virgen de los Dolores

\begin{tabular}{|c|c|c|}
\hline Altares e imagen principal & Cuadros & Imágenes de bulto \\
\hline $\begin{array}{l}\text { Camarín de la Virgen de los Dolores } \\
\text { con puerta de acceso desde la capilla } \\
\text { de Ana de Otálora }(\mathbf{J})\end{array}$ & Señor de la Columna & $\begin{array}{l}\text { Virgen de bulto con } \\
\text { peana dorada y cruz } \\
\text { forrada en carey }\end{array}$ \\
\hline \multicolumn{3}{|l|}{ Columnas doradas sin imágenes $(\mathbf{K})$} \\
\hline \multicolumn{3}{|l|}{ Columnas doradas sin imágenes $(\mathrm{L})$} \\
\hline \multirow[b]{2}{*}{ Redentor $(\mathbf{M})$} & La Trinidad & \\
\hline & $\begin{array}{l}\text { Ánimas (en los } \\
\text { ángulos la muerte, el } \\
\text { infierno, la gloria, la } \\
\text { Trinidad) }\end{array}$ & \\
\hline \multirow{3}{*}{ Virgen de la Antigua $(\mathbf{N})$} & Santa Gertrudis & \\
\hline & Santa Rita de Casia & \\
\hline & Dios & \\
\hline $\begin{array}{l}\text { El Transito de San Nicolás de } \\
\text { Tolentino }(\tilde{\mathbf{N}})\end{array}$ & Niño Jesús & \\
\hline La Ascensión (O) & & \\
\hline
\end{tabular}

Fuente: AHC, SCOA, Carta cuenta I832. 
En 1939, Salamanca Aguilera pudo observar la desaparecida y pequeña ermita de Las Nieves, reemplazada por la actual iglesia en ladrillo de la década de 1960, construida por los salesianos. Allí encontró un altar de la Virgen de Chiquinquirá, una capilla de la Virgen de los Dolores, en la sacristía cuadros antiguos de la Virgen de Belén, santa Teresa, La Magdalena y san Antonio Abad, así como un cuadro grande de san Juan Nepomuceno (Salamanca 62).

La capilla de la Virgen de la Antigua fue despojada de sus altares, los cuales se trasladaron a la capilla del camarín dentro de la misma iglesia de San Agustín. Los historiadores del arte bolivianos José de Mesa y Teresa Gisbert, en su visita a Tunja en la década de 1960, registraron un cuadro de la Virgen de la Antigua en la iglesia de los jesuitas que atribuyeron a un imitador de Angelino Medoro, el Romano. Este gran lienzo fue robado en enero del 2007, pero en el registro de los Mesa Gisbert se observa a los pies de la Virgen a san Francisco de Asís y a san Agustín, de hábito negro, con la mitra a los pies, que consideramos corresponde a la titular de la capilla de la Virgen de la Antigua (Mesa y Gisbert 33-34).

En la capilla al frente de este camarín, usada como depósito por los hospitalarios, se hallaban 5 frontales y 36 piezas de monumento de Semana Santa.

En la tabla 3 se describe la capilla de la familia de Ana de Otálora, que se encuentra a espaldas del camarín de la Virgen de los Dolores.

\section{$\leftrightarrow$ TABLA 3 .}

Inventario de la capilla de san José o de Ana de Otálora

\begin{tabular}{|c|c|c|}
\hline $\begin{array}{c}\text { Altares e imagen } \\
\text { principal }\end{array}$ & Cuadros & Estatuas de bulto \\
\hline \multirow{5}{*}{$\begin{array}{l}\text { Patriarca san José con } \\
\text { sagrario dorado con san } \\
\text { Ignacio con marco de carey } \\
\text { y un Espíritu Santo de yeso } \\
\text { (P) }\end{array}$} & San Luis Gonzaga & \multirow{5}{*}{$\begin{array}{l}\text { San José y Niño Dios } \\
\text { con potencias de cobre, } \\
\text { vestido y capa de brocado, } \\
\text { cabellera y azucena }\end{array}$} \\
\hline & De la Compañía de Jesús & \\
\hline & Virgen de Chiquinquirá & \\
\hline & San Agustín & \\
\hline & San Nicolás & \\
\hline Santo Domingo (Q) & $\begin{array}{l}\text { Señor de la Columna } \\
\text { pequeño }\end{array}$ & \\
\hline
\end{tabular}

Fuente: AHC, SCOA, Carta cuenta I832. 
Hoy en día la estatua de san José se encuentra en el altar mayor de la recoleta de El Topo, el llamado Trono de las Misericordias. En la Casa del Escribano existe un pequeño cuadro del Señor de la Columna.

En la tabla 4 se describe la capilla de la Virgen de la Antigua, despojada de sus altares, pero no de sus cuadros.

\section{$\leftrightarrow$ TABLA 4 .}

Inventario de la capilla de la Virgen de la Antigua convertida en sacristía

\begin{tabular}{|l|l|}
\hline \multicolumn{1}{|c|}{ Cuadros } & \multicolumn{1}{c|}{ Estatuas } \\
Virgen del Rosario (I) & $\begin{array}{l}\text { Globo color azul en el que se apoya la } \\
\text { representación de la Fe de bulto con la } \\
\text { cruz dorada en la mano derecha (7) }\end{array}$ \\
\hline Crucificado (2) & Salvador del Mundo en relieve (8) \\
\hline San Francisco de Asís (3) & \\
\hline San Fernando Rey (4) & \\
\hline Inmaculada con el Niño (5) & \\
\hline San Ignacio de Loyola (6) & \\
\hline
\end{tabular}

Fuente: AHC, Carta cuenta I832

En I832 los hospitalarios usaban esta capilla como sacristía, la cual conservaba el cuadro de san Fernando rey, quien encontrara la advocación original de la Virgen de la Antigua en la catedral de Sevilla en I248. Fue una advocación muy socorrida por los conquistadores, hay una capilla en la catedral de Santo Domingo; la primera ciudad fundada en Tierra Firme fue llamada Santa María de la Antigua del Darién, y Hernán Cortés envió una generosa donación con destino a la capilla sevillana. La Virgen de la Antigua fue tema clásico de la escuela de pintura tunjana desde Medoro. La capilla tenía además una curiosa y desaparecida alegoría de la Fe, imagen bajo la que fue inhumada la beata Cabañas.

En la figura 2, sobre un plano de la iglesia se ha dispuesto la posible ubicación del inventario de 1832, usando las letras (altares) y números (sacristía) que se encuentran resaltados en las tablas i a 4. 


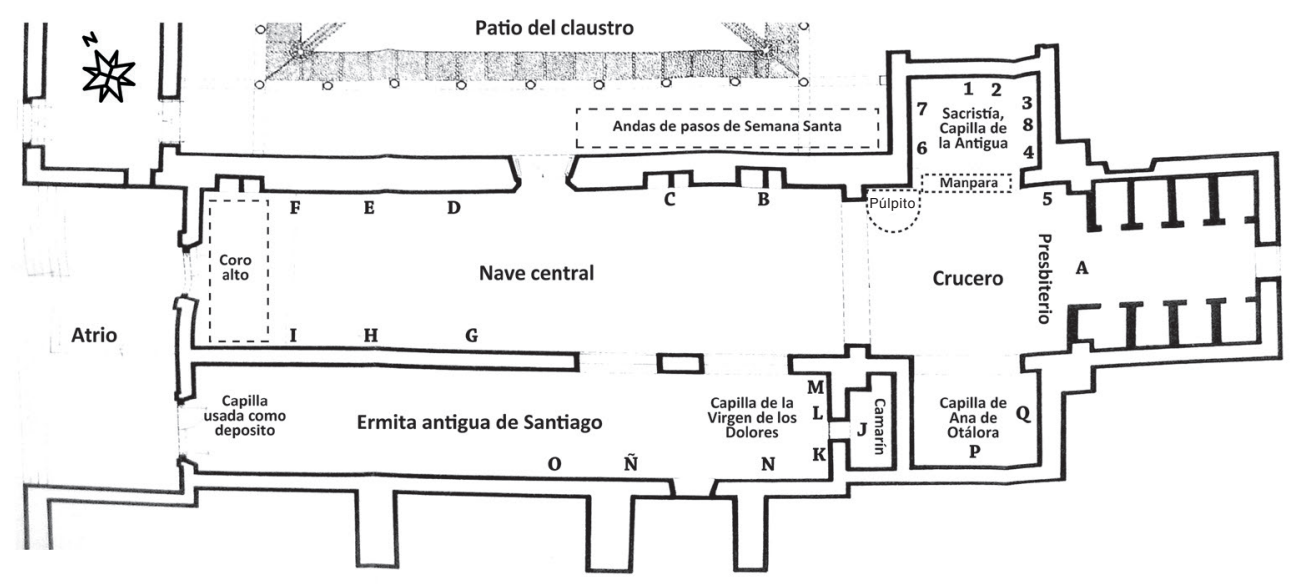

$\leftrightarrow$ FIGURA 2.

Plano e inventario de la iglesia del hospital de Tunja

Fuente: elaboración propia a partir del inventario de I832.

En total se encuentran dieciocho altares en una iglesia que los hospitalarios adaptaron a sus necesidades y que combinaron con las imágenes traídas de su antigua sede y de la iglesia jesuita, imágenes que hoy están dispersas en varias iglesias como el templo de la Compañía, Las Nieves, El Topo, Santa Clara la Real, San Francisco y la Casa Museo del Escribano del Rey; otras fueron trasladadas a Bogotá.

La adaptación para hospital fue la primera de las muchas transformaciones que sufriría el claustro agustino durante el siglo xix. Una de las piezas cuya ventana da a la iglesia se usó como botica, otra, a la derecha de la sacristía, para depositar los cadáveres antes de pasar al cementerio anexo. Varios espacios del convento se adaptaron como jaula para locos, policía del hospital, espacio para preparar las bebidas de los enfermos, ropería y depósito. La cocina se ubicó en la parte posterior, donde existía un aljibe. Por la escalera se accedía a la enfermería de mujeres en el segundo piso, con quince catres, tres ventanas que daban a la calle y un altar dedicado a la Virgen de Chiquinquirá, a los lados Santiago y san Bartolomé y al frente san Juan de Dios. Un cuarto anexo, sin ventanas, servía para la enfermería.

La enfermería de hombres, ubicada en el segundo piso, tenía diecisiete catres, un altar, tres ventanas y siete cuadros de retablo, entre ellos Nuestra Señora del Pilar, san Pedro, Santiago, san Mateo, san Ignacio y san Carlos Borromeo. Al lado de la portería, en el primer piso, se encontraba la tercera enfermería, 
que servía a la tropa con quince catres. En total el hospital tenía 47 camas en I832, la tercera parte ocupada por militares (Martínez, El Hospital I55-I57).

En mayo de 1835 el Congreso de la Nueva Granada comenzó la discusión del proyecto de supresión del convento hospital de Bogotá, que incluyó el cierre del convento tunjano. Los debates concluyeron con la ley del i8 de mayo de i835, que suprimió la Orden Hospitalaria en Nueva Granada (BlaA, SLRM, Pombo).

Al ser extinguida la provincia hospitalaria, Bárbara Niño, hija de un mártir de la Independencia, se encargó caritativamente de los pobres enfermos en asocio del doctor Juan de Dios Tavera. El hospital siguió funcionando en el claustro agustino veinticuatro años más, dependiendo de la caridad pública, hasta que pasó a manos del Estado Soberano de Boyacá en 1855, que en I863 asumió la administración del hospital y decidió trasladarlo. Por Decreto Nacional de i864, el expropiado convento de las clarisas se convirtió en hospital, mientras que San Agustín con su iglesia abandonó la ciudad de Dios y pasó a convertirse en polvorín, cuartel, penitenciaría y panóptico durante cien años. Inició otra etapa de la diáspora de altares, retablos, cuadros y esculturas por las iglesias del casco antiguo de Tunja.

\section{Reflexión final}

Los agustinos llegaron a Tunja tras un tortuoso proceso. El profeso agustino Vicente de Requejada llegó al Nuevo Reino como capellán de la tropa de Federmán y se trasladó con Suárez Rendón a fundar Tunja, donde celebró la primera misa en 1539. Su testamento causó un grave conflicto entre Castellanos y el prior agustino de Santafé, ya que en dicho documento Requejada se reconoció como agustino. El prior agustino, con el argumento de que Requejada era miembro de su orden, inició la reclamación. La Real Audiencia decidió repartir los bienes de Requejada entre la iglesia mayor, la fundación del noviciado agustino en Tunja y los conventos de Santafé y Zaragoza. Los agustinos volvieron a Tunja en 1578 y tomaron posesión de la ermita de Santiago que se incorporó a la iglesia agustina.

Por mucho tiempo no se contó con información de archivo sobre la iglesia agustina, dada la trashumancia de sus obras artísticas en el siglo xix. Curiosamente, fue la República la que hizo posible contar con el único inventario existente de la iglesia de San Agustín hasta ahora, aunque combinado con las 
advocaciones, santos e imágenes que los hospitalarios trajeron de su primitivo convento-hospital y de la iglesia de los expulsados jesuitas.

Este es un primer intento por resignificar las imágenes que permanecen anónimas o atribuidas a otro, imágenes itinerantes y descontextualizadas que se encuentran en ermitas, iglesias y museos de la ciudad, esperando que, al devolverles su contexto, puedan contar la historia del conjunto urbano de Tunja en términos monumentales y visuales, aportando información para los actuales trabajos de restauración que lleva a cabo el Banco de la República.

Según las descripciones del jesuita Solano sobre la vida de la beata Cabañas, de finales del siglo xviI, en Tunja se conocían las alegorías y los atributos de san Agustín. En el ambiente cultural de esta ciudad neogranadina, no resultaban extrañas ni las pinturas murales ni las advocaciones y las imágenes de los altares.

La presencia de la ermita de Santiago y de la capilla de la Virgen de la Antigua en el lugar donde se levantó la iglesia de San Agustín representa una verdadera marca de conquista. Por un lado, el apóstol de la conquista y, por otro, una de las advocaciones de la Virgen relacionada con los conquistadores, sobre el cercado del zaque muisca. Así mismo, otra de las tradiciones de la ciudad, sus procesiones de Semana Santa, se demuestra que salieron de San Agustín en el siglo xix.

El vacío espacio destinado finalmente a la cultura conserva como único testigo de su convulsa historia su pintura mural. Las grandes trasformaciones sufridas para adaptarlo a penitenciaría priman sobre su uso conventual y lo enmascaran. En la historiografía local, urbana y regional, son escasos los estudios sobre el primer conjunto conventual agustino de los siglos XVII y XVIII, en tanto que priman la información y los trabajos sobre la penitenciaría de los siglos XIX y xx. A diferencia de lo planteado, parece que el convento y la iglesia agustina fueron el verdadero patrimonio incómodo y, el cómodo, la penitenciaría.

Esperamos que este texto sea un punto de partida para nuevas investigaciones sobre el importantísimo patrimonio artístico colonial de Tunja en su conjunto, donde haya lugar para análisis iconográficos comparados y documentales que profundicen en la reconstrucción visual y la elaboración de inventarios patrimoniales acordes con las capas históricas de esta ciudad andina. 


\title{
. \\ B I B L I O G R A F í A
}

\section{F F E N T ES PRIMARIAS}

\author{
Archivo Hospitalario Colombiano, Bogotá $(A H C)$, Provincia de San Bernardo \\ y Tierra Firme \\ Sección Comunidades y Obras Apostólicas-casas ( $\mathrm{SCOA})$ \\ Caja 6 \\ Carta Cuenta e inventario del Convento Hospital de Tunja, I831 y I832.
}

Biblioteca Luis Ángel Arango, Bogotá ( $B L A A)$

Sala de Libros Raros y Manuscritos (SLRM)

Pombo, Lino de. Recopilación de Leyes de la Nueva Granada. Bogotá: Imprenta de Zoilo Salazar, por Valentín Martínez, i845.

Biblioteca Nacional de Colombia, Bogotá $(B N C)$

Sección Libros Raros y Manuscritos, Fondo Antiguo (SLRM)

Solano, Diego. Ilustre y penitente vida de la venerable vida de la Virgen Doña Antonia de Cabañas. Manuscrito, s. f.

Biblioteca Nacional de España, Madrid $(B N E)$

Valencia, Pedro de. Descripción de Indias T. I. Descripción de la ciudad de Tunja, sacada de las informaciones hechas por la justicia de aquella ciudad en 30 de mayo de I6Io años. Manuscrito, siglo XVII. Mss/3064, ff. 242 v.-267 v.

John Carter Brown Library, Providence, Rode Island (JCBL), Peru Collection.

Torres, Bernardo de. Crónica de la Provincia Peruana del Orden de los Ermitaños de San Agustín nuestro padre. Lima: Imprenta de Julián Santos de Saldaña, 1657.

\section{I F U E N T ES S E C U N D A R I A S}

Agudelo, Benjamín. Los hijos de San Juan de Dios en Nueva Granada, t. II. Cali: Carvajal, 1983.

Campo del Pozo, Fernando. "Fuentes para la historia de los agustinos en el Nuevo Reino de Granada”. Archivo Agustiniano, n. ${ }^{\circ}$ 73, 1989, pp. 257-276.

---. "Historia de la provincia de San Miguel de Quito en el Nuevo Reino de Granada durante el siglo Xvi”. Estudio Agustiniano, n. ${ }^{\circ}$ Io, 1975, pp. 269-310.

Carmona Muela, Juan. Iconografía de los santos. Madrid: Akal, 2008. 
Castellanos, Juan de. Elegías de Varones Ilustres de Indias. Bogotá: Gerardo Rivas Moreno, 1997.

Chuaqui, Tomás. "La Ciudad de Dios de Agustín de Hipona: selección de textos políticos". Estudios Públicos, n. ${ }^{99}$, 2005, pp. 273-390. Dor: https://doi.org/10.38178/cep.vi99.615.

Colmenares, Elkin. Entre la falsificación y la supervivencia del pasado. Luis Alberto Acuña y la intervención a la casa del escribano Juan de Vargas. Tunja: Ediciones UsTA, 2019.

Fundación para la conmemoración del bicentenario del natalicio y el sesquicentenario de la muerte del general Francisco de Paula Santander. Acuerdos del Consejo de Gobierno de la República de Colombia I824-I824, t. I. Bogotá: Biblioteca de la Presidencia de la República, 1988.

Herrera, Francisco y Liliana Vargas. "En los orígenes de la retablística neogranadina: trazas y contrato para un retablo de Tunja (1586)". Laboratorio de Arte, n. ${ }^{\circ}$ 29, 2017 , pp. 207-22 8. DOI: https://doi.org/10.12795/la.2017.i29.10.

Kamen, Henry. La Inquisición española. Mito e historia. Barcelona: Crítica, 2013.

López, María del Pilar. "La vida en casa en Santa Fe en los siglos XviI y XviII”. Historia de la vida privada en Colombia. T. I. Las fronteras difusas del siglo XVI a I880, editado por Jaime Borja y Pablo Rodríguez. Bogotá: Taurus, 20II, pp. 8I-I07.

Martínez, Abel. “El claustro de San Agustín de Tunja: Una historia de múltiples encierros”. Pensamiento y Acción, n. ${ }^{\circ}$, 2001, pp. I25-129.

---. El Hospital de la Purísima Concepción de Tunja. Tunja: Universidad Pedagógica y Tecnológica de Colombia, 2019.

Martínez, Abel y Andrés Otálora. "Iglesias y altares del Hospital de la Purísima Concepción de Tunja (I553-1835)”. Laboratorio de Arte, n. 31, 2019, pp. I6I-I84. DoI: https://doi. org/ı.12795/la.2019.i3ı.ı.

Mercado, Pedro de. Historia de la Provincia del Nuevo Reino de Granada y Quito de la Compañia de Jesús. T. I, Bogotá: Presidencia de la República de Colombia, 1957.

Mesa, José de y Teresa Gisbert. "El pintor Angelino Medoro y su obra en Sud América". Anales del Instituto de Arte Americano e Investigaciones Estéticas, n. ${ }^{\circ}$ 8, 1965 , pp. 27-67.

Mier, José de. La Gran Colombia. T. I. Decretos de la Secretaría de Estado y del Interior I82II824. Bogotá: Presidencia de la República, 1983.

Mucientes, David. Centurias colombo-agustinas I525-1967. Bogotá: Talleres Salesianos, 1968.

Paniagua Pérez, Jesús. “Magne Pater Agustine: La exaltación agustiniana en las pinturas del Convento de Tunja". Archivo Agustiniano, n. ${ }^{\circ}$ 203, 2001, pp. 193-229.

Parodi, Massimo. "Agustín de Hipona”. La Edad Media. Bárbaros, cristianos y musulmanes, coordinado por Umberto Eco. México: Fondo de Cultura Económica, 2015, pp. 349-359. 
Rojas, Ulises. El beneficiado Juan de Castellanos cronista de Colombia y Venezuela. Bogotá: Selene, 1997.

Salamanca Aguilera, Rafael. Guia histórica ilustrada de Tunja. Bogotá: Escuelas Gráficas Salesianas, 1939 .

Sebastián, Santiago. Album de arte colonial de Tunja. Tunja: Imprenta Departamental, 1963.

---. Contrarreforma y Barroco. Madrid: Alianza, 1981.

Sigaut, Nelly. "San Agustín en Hispanoamérica: circulación de una serie hagiográfica". Migraciones y rutas del Barroco, editado por Fundación Altiplano. La Paz: Fundación Visión Cultural, 2014, pp. IOI-II2.

Vallín, Rodolfo. Imágenes bajo cal y pañete. Pintura mural de la Colonia en Colombia. Bogotá: El Sello Editorial-Museo de Arte Moderno, 1998.

Young, John Lane. La Reforma universitaria en Nueva Granada. Bogotá: Universidad Pedagógica Nacional; Instituto Caro y Cuervo, 1994. 